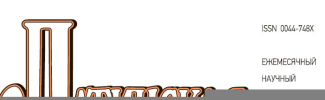

Латинская Америка. 2013-2023

ISSN 0044-748X

URL - $\underline{\text { http://latamerica-journal.ru }}$

Все права защищены

Выпуск № 2 Том . 2021

\title{
Морская проблема Боливии
}

\section{Селиванова Ирина Валентиновна \\ Институт всеобщей истории РАН \\ Российская Федерачия, Москва}

\section{Аннотация}

В данном материале подробно рассмотрена новая монография российского латиноамериканиста, д-ра ист. наук, ведущего научного сотрудника Института всеобщей истории РАН Андрея Аркадьевича Щелчкова. Отмечается, что книга представляет собой первое фундаментальные исследование чилийскоболивийского территориального конфликта и многолетней борьбы Боливии за выход к тихоокеанскому побережью. Автор монографии исследует истоки этой политической и дипломатической проблемы, а также фиксирует наиболее важные этапы ее развития. Издание представляет несомненную ценность для специалистов, а также всех, кто интересуется историей стран Латинской Америки.

ключевые слова: Боливия, Чили, Перу, Тихоокеанская война, Атакама, чилийскоболивийский территориальный конфликт

Дата публикации: 08.02.2021

\section{Ссылка для цитирования:}

Селиванова И. В. Морская проблема Боливии // Латинская Америка. - 2021. Выпуск № 2 C. 95-102 . URL: https://latamerica-journal.ru/s0044748x0013157-1-1/. DOI: $10.31857 / \mathrm{S} 0044748 X 0013157-1$

1 Территориальные споры, затрагивающие не только вопросы государственных границ, но и влияющие на политическое, экономическое, культурное развитие государства и даже на психологическое состояние народов тех или иных стран, остаются одной из самых серьезных международных проблем 
современности. К такому типу конфликтов можно отнести многолетний чилийскоболивийский спор по вопросу выхода Боливии к морю. Истоки этого территориального конфликта берут начало в XIX в. и во многом обуславливаются колониальным прошлым этих государств.

2 Чилийско-боливийский территориальный конфликт, в результате которого Боливия потеряла выход к морю и до сих пор его лишена, представляет собой одну из самых печальных страниц боливийской истории, являясь одновременно серьезной политической проблемой в рамках дипломатических отношений двух латиноамериканских стран. Выход в свет монографии известного отечественного латино- американиста А.А.Щелчкова «Драма заточения страны: чилийскоболивийский конфликт и проблема выхода Боливии к морю» [1] стал ярким событием в российской латиноамериканистике и, без сомнения, не останется незамеченной в научном сообществе. Презентация книги была приурочена к празднованию национального дня Боливии и состоялась в Москве в Ибероамериканском культурном центре при поддержке посольства Многонационального государства Боливия.

3 Следует отметить, что крупный территориальный конфликт, крайне болезненный как минимум для трех латиноамериканских государств - Боливии, Чили и Перу, - имеющий давнюю историю и нерешенный до настоящего времени, постоянно находится в поле зрения как отечественных, так и зарубежных латиноамериканистов. При этом каждый новый всплеск исследовательского интереса к этому вопросу во многом объясняется событиями очередного этапа в решении международного территориального спора.

4 Часть исследований посвящено одному из ключевых этапов чилийскоболивийского конфликта - Тихоокеанской войне (1879-1883 гг.). Среди них можно назвать работы боливийского историка и адвоката Р.Керехасу Кальво [2, p. 36; 3]. Заслуживает внимания и монография Карлоса Диего Месы Хисберта, бывшего президента Боливии (2003-2005 гг.), «История боливийского моря» [4], поскольку во время его правления власти страны заняли весьма активную позицию по «морскому вопросу», выработав новую стратегию в отношении Чили - «газ за море». Как отмечает А.А.Щелчков, лучше всего эта позиция была выражена самим президентом Боливии: «Ни капли газа Чили» [2, с. 143]. Следует также назвать исследования авторитетного историка Тихоокеанской войны Р.Б.Сент Джона [5, 6], одно из которых - «Боливия: геополитика государства, не имеющего выхода к морю» — вышло в свет в 2019 г. [7].

5 Конечно, боливийские историки также не оставляли без внимания «морскую проблему». Так, можно отметить работы В.Абесии Вальдивиесо боливийского адвоката, историка и министра иностранных дел (1989-1990 гг.), посвященные международной политике страны и, в частности, борьбе за выход к морю $[8,9]$. В работах боливийского исследователя реваншистского толка, известного историка и дипломата Хорхе Эксобари Кусиканки $[10$, р. $273 ; 11$, р. 275], выдвигались прямые требования возврата морского побережья, а также обосновывалась необходимость прибегнуть к международному давлению для получения нужного стране результата. Внешнеполитические отношения Боливии с 
Чили он квалифицировал как «аморальную дипломатию для достижения безнравственных целей» [12, с. 43].

6 О важности чилийского-боливийского территориального конфликта красноречиво говорит тот факт, что исследования по этому вопросу появляются и в наше время. Авторы некоторых из них являются дипломатами и отмечают, что затянувшийся исторический спор существенно влияет на отношения Чили и Боливии сегодня, а также определяет их внешнюю политику в целом [13, с. 47]. Ключевому событию чилийско-боливийского территориального конфликта заключению договора 1904 г. - посвящена работа известного боливийского историка Хорхе Силес Салинеса [14], приуроченная к столетию договора. А.А.Щелчков отмечает, что историк довольно резко осудил соседа Боливии Чили, обвинив ее в безжалостности и жестокости при заключении мирного договора [1, с. 118].

7 Различные сюжеты чилийско-боливийского территориального спора уже были освещены в отечественной латиноамериканистике [15]. Так, Тихоокеанской войне были посвящены специальные разделы в коллективных работах [16, 17]. В статье Н.С.Иванова не только анализируются предыстория возникновения конфликта, причины и ход Тихоокеанской войны, но и освещается деятельность английского капитала, заинтересованного в контроле над ресурсами гуано и селитры [18, с. 49-72]. Раскрытию основных этапов чилийско-боливийского морского конфликта посвящена статья ведущего научного сотрудника ИЛА РАН, д-ра политических наук Л.В.Дьяковой [19, с. 124-147]. В центре внимания петербургских авторов - В.Л.Хейфеца и Д.А.Правдюк - оказались отношения между Чили и Боливией в период 2011-2015 гг., прежде всего ситуация, связанная с обращением Боливии в Международный суд в Гааге по территориальному спору [20, с. 125-148], а также анализ проблем, мешающих обеим странам поддерживать диалог и найти взаимоприемлемый компромисс [21, c. 60-72].

8 Но, несмотря на интерес многих латиноамериканистов к указанному выше вопросу, следует отметить, что до сих пор в российской латиноамериканистике не было комплексного исследования, посвященного чилийско-боливийскому конфликту. Монография А.А.Щелчкова в значительной степени восполнила этот пробел. Безусловным достоинством работы является то, что она представляет собой многоплановое исследование «морской» проблемы Боливии. Автор показывает исторические причины потери страной выхода к морю, описывает процесс освоения тихоокеанского побережья, раскрывает внешнеполитические и экономические предпосылки чилийско-боливийской конфликта. Серьезное внимание историк уделяет освещению попыток дипломатического урегулирования конфликта, позиции по этому вопросу Великобритании и США. А.А.Щелчков предпринимает весьма успешную попытку разобраться в тонкостях и сложностях международного конфликта и болезненного для обеих стран вопроса, сохраняя при этом историческую объективность и многофакторный подход, несмотря на нескрываемую симпатию к Боливии и убежденность в существовании у нее исторических прав на тихоокеанское побережье. 
В первых двух главах автор предлагает разобраться в исторической принадлежности пустыни Атакамы, поскольку, как он справедливо замечает, ни до независимости Боливии, ни после ее обретения не было ясного понимания того, где заканчивается Чили и начинается Боливия. Однако, несмотря на это, историк упоминает важный законодательный акт испанский короны - ордонанс 1782 г., в котором Атакама прямо названа частью интендантства Потоси, входившего в аудиенсию Чаркас с центром в городе Чукисака (Ла-Плата). На основании этого А.А.Щелчков делает вывод о принадлежности этой территории на тихоокеанском побережье Чаркас современной Боливии.

10 Автор подробно описывает сложности, с которыми сталкивалась Боливия, в частности, преодоление пустыни Атакамы, в процессе выхода к тихоокеанскому побережью для вывоза из страны серебра и других экспортных товаров. Исследователь указывает на особенность развития этого региона, когда, несмотря на наличие собственного порта на побережье - г. Кобихи, - Боливия чаще использовала для торговли перуанский порт Арику. В работе подробно описываются попытки боливийского правительства изменить ситуацию в лучшую сторону, но, несмотря на все усилия, город был разрушен в результате мощного землетрясения 1877 г.

11 Автор справедливо подчеркивает, что звездный час в развитии Литораля (побережья Боливии) наступил только после открытия здесь залежей ценного сырья - гуано-селитры, что обусловило мировой интерес к этому региону и в середине XIX в. вызвало в Европе гуано-селитряный бум [1, с.25]. Историк указывает на изменение экспортной направленности экономики страны: если до середины XIX в. Боливия особо ценилась на мировом рынке, прежде всего, как поставщик серебра, меди и олова, то с этого момента на первый план вышел вывоз гуано и хинина [1, с. 27]. Именно обнаружение запасов селитры и гуано, как считает автор, обострило территориальный вопрос, поскольку Чили и Боливия претендовали на всю территорию пустыни. Боливия утверждала, что ее территория простиралась до $25^{\circ}$ южной широты, а Чили доказывала, что граница проходит по $23^{\circ}$.

12 Особый интерес представляет третья глава монографии, посвященная путевым заметкам иностранных путешественников, посетивших боливийское побережье. Этот тип исторического источника является особенно ценным в связи с тем, что первыми путешественниками были, как правило, либо ученые, либо дипломаты. Соответственно, их заметки, кроме простого описания, содержат проекты освоения новых независимых территорий. Благодаря тому, что путешественники совмещали дипломатические, научные, a нередко и предпринимательские интересы, они оставляли действительно интересные, богатые фактическим материалом записи, ставшие важным историческим источником того времени. Именно поэтому А.А.Щелчков часто цитирует путевые заметки, что позволяет не только передать колорит описываемых территорий, но и раскрыть истинные причины и задачи путешественников.

13 Четвертая глава книги посвящена истокам чилийско-боливийского территориального конфликта. Необходимо отметить, что и Боливия, и Чили могли претендовать на территорию пустыни Атакамы, поскольку четкая граница двух 
стран не была определена. Это и обусловило тот факт, что пустыня, находившаяся на стыке трех государств (Боливии, Чили и Перу), превратилась в «яблоко раздора».

14 Автор справедливо обозначает начало конфликта между Чили и Боливией периодом 1833-1834-х годов, когда во время правления Андреса де Санта Круса (1829-1939 гг.) возникла возможность объединения Перу и Боливии. А появление в Южной Америке столь мощного государства было крайне опасно для Чили. В этом разделе монографии описываются территориальные претензии Боливии и Чили в отношении пустыни Атакамы с учетом географических сложностей решения этого вопроса: провести четкую границу между странами по территории пустыни невозможно.

15 Автор монографии показывает, что обнаружение богатых залежей гуано обострило противоречия между странами и привело к оккупации в 1861 г. со стороны Чили боливийского порта Мехильонес. А.А.Щелчков подробно описывает сложную внешнеполитическую обстановку, когда, несмотря на серьезные противоречия с Чили, Боливия в 1866 г. в знак солидарности поддержала Перу и Чили в их борьбе против испанской агрессии. Ученый критикует подписанный в 1866 г. договор между Боливией и Чили, «который изначально признавал ущербность собственного суверенитета на побережье» [1, с. 61], а фактически передвигал границу на один градус южной широты на север, в результате чего, кроме потерь от добычи гуано, селитры и других материалов, также страдал боливийский порт Кобиха. В этом же разделе историк раскрывает предпосылки подготовки Тихоокеанской войны, отмечая, что главным преимуществом Чили в предстоящем конфликте стало то, что «чилийская нация была более сплоченной, расово однородной, это была сформировавшаяся современная гражданская нация» [1, с. 71].

16 Пятая глава монографии посвящена собственно освещению Тихоокеанской войны (1879-1883 гг.). Обусловленная крупнейшим мировым экономическим кризисом, обострившим отношения между тремя тихоокеанскими странами, война стала одним из самых драматичных событий, происходивших на южноамериканском континенте в то время. Серьезное внимание автор уделяет описанию позиции Великобритании в этом конфликте. Как справедливо отмечает исследователь, удар по селитряным копиям, принадлежавшим английским компаниям, в провинции Тарапака обусловил поддержку Чили со стороны Британии. Историк освещает противостояние интересов Соединенных Штатов и Чили, вынужденных поддерживать Перу и Боливию в силу опасения аннексионистских намерений чилийцев. На фоне подробного описания военных баталий А.А.Щелчков рассматривает и дипломатические отношения между Британией и США, занявших противоположные позиции в этом конфликте. По результатам перемирия, достигнутого между Чили и Боливией 4 апреля 1884 г. в Вальпараисо, последняя лишилась области Антофагаста и, соответственно, выхода к морю. Этот документ заложил основу договора, заключенного в 1904 г.

17 Мирный договор от 20 октября 1904 г., подписанный в Сантьяго и ставший важнейшей вехой в новой расстановке сил в регионе автор монографии справедливо оценивает как «самый драматический по своим последствиям и 
позорный для Боливии внешнеполитический документ, на многие годы лишивший страну надежды на восстановление своего статуса как морской державы, обрекавший ее на заточение и изоляцию в центре американского континента» [1, c. 117]. Историк однозначно дает понять, что, несмотря на денежную компенсацию в 300 тыс. фунтов стерлингов, а также обязательство чилийского правительства построить железную дорогу Арика - Ла-Пас и предоставить Боливии право свободного, беспошлинного транзита своих товаров через чилийские порты $[1, \mathrm{c}$. 358], подписание этого договора означало для Боливии потерю суверенитета над тихоокеанским побережьем. В доказательство своей позиции А.А.Щелчков приводит мнение современного боливийского историка Хорхе Силеса Салинаса, который назвал этот дипломатический акт «пораженчеством и географическим безумием» $[14$, с. 669-670]. Учитывая крайне несправедливые условия договора, Боливия на протяжении всего XX в. пыталась оспорить навязанный ей мирный договор 1904 г.

18 В последующих четырех главах ученый освещает неудавшиеся попытки Боливии путем дипломатических переговоров решить «морской» вопрос на протяжении всего XX в. Историк детально описывает, как боливийская дипломатия безуспешно ставила вопрос о выходе к морю в Лиге наций в начале 20-х годов XX в. и в Организации американских государств в конце 50-х годов XX B..

19 Многолетний чилийско-боливийский территориальный спор превратился в актуальный вопрос внешней политики обоих государств в 70-е годы XX в. В связи с этим заключительные главы монографии автор посвятил обзору событий, развивавшихся с 70-х годов XX в. по настоящее время. А.А.Щелчков обозначает новый этап в решении наболевшего вопроса Боливии и особое значение придает исторической встрече двух правителей - генералов Уго Бансера и Аугусто Пиночета, состоявшейся 8 февраля 1975 г. [1, с. 135]. Как справедливо отмечает историк, подписанная в то время декларация означала фактическое восстановление дипломатических отношений между странами, разорванных в 1962 г. Ученый указывает, что позиции Боливии, Чили и Перу, т.е. стран участниц территориального конфликта, привели к провалу попытки решения морского вопроса и к новому разрыву дипломатических контактов между Боливией и Чили, произошедшему в октябре 1977 г.

20 В последней главе монографии освещается состояние территориального конфликта в XXI в., который в это время вышел на первый план внешней политики Боливии благодаря деятельности президента Карлоса Месы. Как отмечает А.А.Щелчков, К.Меса связал вопрос поставок газа Чили с решением территориального спора, что подогрело интерес к этому вопросу на международной арене в целом. В этом разделе монографии историк также рассматривает политику боливийского президента Эво Моралеса (22 января 2006 г. - 10 ноября 2019 г.). Выражая интересы «блока антиимпериалистических и антинеолиберальных сил» в стране, Моралес, как подчеркивает автор, взял курс «на возвращение стране ее законных прав и статуса морской державы» [1, с. 143]. А.А.Щелчков указывает на появление перспектив в решении сложного вопроса получения Боливией выхода к морскому побережью. Он отмечает, что в то время была выработана новая трактовка военного и политического противостояния 
Боливии и Чили, в рамках которой главный акцент смещается на империалистический характер Тихоокеанской войны, обусловленный интересами английского империализма, пытавшегося руками Чили обеспечить соблюдение собственных интересов [1, с. 144]. Автор описывает нынешние события, из-за которых, несмотря на сменяющие друг друга периоды дипломатического сближения и отдаления, двум странам, разделенным «морской проблемой», до сих пор не удается решить многолетний территориальный конфликт.

21 Следует отметить, что большинство задач, которые были поставлены автором монографии, успешно решены. Однако, к сожалению, А.А.Щелчков, не включил в работу историографический раздел, где, на наш взгляд, можно было бы отразить уровень исследования изучаемой исторической проблемы и показать основные направления, в рамках которых она освещается в настоящее время. Кроме того, события последних десятилетий, связанные с урегулированием территориального конфликта, в частности, рассмотрение спора в Гаагском международном суде, а также переговоры президентов Боливии и Чили, описанные в последней главе работы, стоило бы рассмотреть более подробно, учитывая тот факт, что обращение Боливии в международный суд придает межгосударственному спору качественно иной статус. Однако эти незначительные замечания ни в коей мере не умаляют достоинств фундаментального научного исследования, написанного с позиций последовательного историзма хорошим литературным языком.

22 Детальное изучение исторических источников и литературы позволили автору успешно решить поставленные задачи. Работа представляет несомненную ценность не только для специалистов, но и для широкого круга читателей, интересующихся историей Латинской Америки, для преподавателей и студентовисториков.

\section{Библиография:}

1. Щелчков А.А. Драма заточения страны: чилийско-боливийский конфликт и проблема выхода Боливии к морю. М., Аквилон, 2019, 160 с.

2. Querejazú Calvo, R. La Guerra del Pacifíco. La Paz and Cochabamba. Editorial Los Amigos del Libro, 1983, 148 p.

3. Querejazú Calvo, Roberto Guano, Salitre, Sangre: Historia de la Guerra del Pacífíco, La Paz and Cochabamba: Editorial Los Amigos del Libro, 1992, 825 p.

4. Mesa Gisbert Carlos D. La historia del mar boliviano. Editorial Gisbert La Paz, 2016, 310 p.

5. St. John R.B. The Bolivia-Chile-Peru Dispute in the Atacama Desert. Boundary and Territory Briefing, 1994, V. 1, N 6, p. 1-38

6. St John, R.B. Hacia el Mar: Bolivia's Quest for a Pacific Port. Inter-American Economic Af-fairs, 1977, N 31, 3 p. 41-7. 
7. St. John R.B. Bolivia: Geopolitics of a Landlocked State. London, Routledge. 2019, $248 \mathrm{p}$.

8. Abecia Baldivieso V. Las relaciones internacionales en la historia de Bolivia. Tomo III. La Paz: La Paz : Editorial Los Amigos del Libro, 1986.

9. Abecia Baldivieso V. La dramática historia del mar boliviano. La Paz: Librería Editorial "Juventud", 1986, 171 p.

10. Escobari Cusicanqui J. El derecho al mar. La Paz, Librería Editorial «Juventud», $1964,312 \mathrm{p}$.

11. Escobari Cusicanqui J. Historia diplomática de Bolivia. (Política internacinal). La Paz, Litografías Unida, 1979, 350 p.

12. González Miranda S. y Ovando Santana C. "Emotivistas" bolivianos en la relación diplomática entre Bolivia y Chile en torno a la mediterraneidad. Estudios Internacionales, Santiago, 2016, N 183, p. 39-65.

13. Francisco Mila F. La cuestión marítima en la política exterior de Chile y Bolivia. Diplomacia, 2009, N 118, p. 47-69.

14. Siles Salinas J. El tratado de 1904: enemistad y fracaso. Anuario de estudios bolivianos, archivísticos y bibliográficos. Sucre, 2004, N 10, p. 669-676.

15. Пугаева С.М. Боливия и море. Латинская Америка, Москва, 1978. № 5, с. 168175. [Pugaeva S.M. Boliviya i more [Bolivia and the sea]. Latinskaya Amerika, Moscow, 1978, № 5, p. 168-175. (In Russ.).

16. История Боливии с древнейших времен до начала XXI века (отв. ред. Е.А.Ларин, А.А.Щелчков). М., Институт всеобщей истории РАН, 2015, 699 с.

17. История Перу с древнейших времен до конца XX века. М.: Наука, 2000, 476 с.

18. Иванов Н.С. Тихоокеанская война (1879-1883). Региональные факторы и роль британского капитала. Латиноамериканский исторический альманах, Москва, 2015, Институт все-общей истории РАН, № 14, с. 49-72.

19. Diyákova L.V. Conflicto marítimo boliviano-chileno: antecedentes y perspectivas de arreglo. Iberoamérica, Moscú, 2017, N 2, pp. 124-147.

20. Jéifets V.L., Pravdiuk D.A. El papel de la Corte de la Haya en la solución de litigios territoriales en los países de América Latina y del Caribe en el siglo XXI. Iberoamérica, Moscú, 2019, N 3, pp. 125-148.

21. Хейфец В.Л., Правдюк Д.А. Современные чилийско-боливийские отношения в контексте поиска решения «морской проблемы» Боливии. Латинская Америка, 2015, Москва, № 9, с. 60-72. 


\title{
Bolivia's sea problem
}

\section{Julia Selivanova}

Institute of World History, RAS

Russian Federation, Moscow

\begin{abstract}
The publication acquaints readers with a new serious research of the famous Russian Latin Americanist, Doctor of Historical Sciences, leading researcher of the Institute of General History of the Russian Academy of Sciences A.A.Schelchkov "The drama of the imprisonment of the country: the Chilean-Bolivian conflict and the problem of Bolivia's access to the sea." The review provides a detailed description of the monograph. It is noted that the publication is the first fundamental investigation of the Chilean-Bolivian territorial conflict and the long-term struggle of Bolivia to obtain its own access to the Pacific coast. The review notes that the author of the monograph explores the historical origins of this political and diplomatic problem, and also records the most important stages of its development. The publication is of undoubted value for specialists, as well as everyone who is interested in the history of Latin America.
\end{abstract}

Keywords: Bolivia, Chile, Peru, Pacific War, Atacama, Chilean-Bolivian territorial conflict

Date of publication: 08.02 .2021

\section{Citation link:}

Selivanova J. Bolivia's sea problem // Latinskaia Amerika. - 2021. - Issue 2 C. 95-102 . URL: https://latamerica-journal.ru/s0044748x0013157-1-1/. DOI:

\subsection{7/S0044748X0013157-1}

